\title{
William Carlos Williams' cubism: The sensory dimension
}

\author{
Jan-Louis Kruger \\ Department of English \\ Potchefstroom University for CHE \\ Vaal Triangle Campus \\ VANDERBIJLPARK
}

Cubism as a whole complicates the idea of the present as something which can be simply identified, as something which we are in possession of and which we can identify with immediately ... Cubist art concerns itself with an indivisible unfamiliarity which permeates our experience of the present and our involvement with it.

Timothy Mathews: Apollinaire and Cubism? (1988)

\section{Abstract}

\section{William Carlos Williams' cubism ${ }^{1}$ : The sensory dimension}

In this article the cubism of the American poet William Carlos Williams is discussed as a product of sensory elements combined with techniques derived from the work of the visual artists associated with this style. Through the study of a number of poems written in the period between 1917 and 1923 it is shown that Williams employs the cubist intersection of sensory planes in particular to create a sensory dimension that not only renews the traditions and mode of poetry, but also reveals the cubist concern with the defamiliarization and foregrounding of fragments of everyday experiences. Ultimately the article is an attempt to indicate Williams' incorporation of a sensual dimension in creating a style that achieves modernist presentation

When used with an upper-case ' $C$ ', Cubism / Cubist refers to the movement of Cubism in the visual arts around the first two decades of the century (1900-1915). A lower-case ' $c$ ' is used (cubism / cubist) to indicate both literary and visual styles which share many characteristics with Cubism but do not belong to that specific movement. It further indicates the general spirit of the style without limiting it to the work of the visual artists normally associated with Cubism. 
revealing an independence from both traditional literary and visual styles.

\section{Introduction}

In cubism ${ }^{2}$ the modernist search for the new confounds 'traditional' concepts of order, aesthetics and perspective. The central concern of this article is to show the cubism of the American poet William Carlos Williams to be a foregrounding of the "experience of the present", a defamiliarization in which the "indivisible unfamiliarity" (Mathews, 1988:289) of experience is presented as a product of sensory perceptions. However, this article by no means intends to suggest that Williams' cubism is dependent exclusively on the sensory dimension of his poems.

An attempt will therefore be made to show that the poetry of William Carlos Williams (in attaining this defamiliarized rendering of the experience of the present moment) is profoundly cubist and at the same time more comprehensive than mere visual presentation, in the dimensions created by the senses.

The article also examines Williams' degree of success in bringing the literary genre of poetry to the 'concrete' or visual level of painting in order to justify terming some of his poems cubist. Specifically the role of the techniques and characteristics of cubism in the literary genre of poetry will be examined, not in making the poems visual at the cost of literary qualities, but rather in exploring the way in which Williams employs these elements to enhance and invigorate the medium of poetry.

Williams' use of the cubist intersection of planes ${ }^{3}$, particularly sensory planes, results in poetry that is richer than mere attempts at visuality or

2 In The Dictionary of Literary Terms, Shaw (1972:102) defines cubism as a style of painting and sculpture that "emphasises the formal structure of a work of art and the reduction of natural forms to geometric equivalents". Shaw then continues to define cubist poetry as attempting to "fragment the elements of an experience and then to rearrange them in a new synthesis".

3 According to Burbick (1982:112), the Cubists used shifting planes to analyze the 'object' and thus translated a figure or still-life into a sequence of intersecting planes within a shallow depth. In the words of Mathews (1988:286), Cubists sought "to exploit the flatness of the canvas to suggest anything that is not flat". 
imitations of the work of the visual artists. A few of Williams' earlier cubist poems written in the years after 1917 and before the climax of his cubist phase in Spring and All (1923) ${ }^{4}$, reveal the manifestation of these elements.

\section{Poetic cubism - a definition}

The relationship between the visual and literary arts and specifically the influence of developments in painting on poetry is evident in modernist poetry in, for example, the images created by the imagists, but even more so in the poetry termed cubist.

Cubism in the printed poem would refer to a style in which juxtaposition is employed with a sense and appearance of edges in the form of vocabulary, various contrasts (also of the senses), and a general hardness. The principles of the style mainly centre in the move to presentation away from representation.

Though primarily a style in the visual arts, cubism is exactly that, a style, transcending boundaries of genre and mode and intimating a general attitude of originality, of making new through techniques of defamiliarization. The style is a view or perspective on 'reality' and life which is also manifested in literature.

Cubism was linked with poetry as early as the first decade of the twentieth century by the French poet Guillaume Apollinaire, who fashioned some of his work in accordance with the paintings of leading Parisian Cubists such as Picasso and Matisse ${ }^{5}$. William Carlos Williams was likewise fascinated

$4 \quad$ Although this period is almost a decade later than the originating of Cubism in the visual arts, it is the period in which Williams' work most clearly demonstrates characteristics that can be linked to endeavours in the visual arts.

It is important at this stage to keep in mind that Williams was never a Cubist in the sense of belonging to the group or 'school' of Cubism, but that he rather employed cubist techniques in his individual poetic style.

$5 \quad$ Timothy Mathews' article, "Apollinaire and Cubism?" (1988), gives an account of the effect of Apollinaire's theorizing about Cubist paintings on his poetic development. 
by the direction taken by the modernist painters to whose work he was introduced specifically in the period surrounding the New York Armory Show of $1913^{6}$.

In America the adoption of the techniques of the visual arts in poetry also became manifest in the work of a number of modernist poets. "Soon", in the words of Bram Dijkstra (1978:5),

Marianne Moore, Williams, Stevens, and a number of others were to turn away from the sterility of the literary atmosphere around them and to seize upon the hints of innovation in the visual arts which began to filter through to them from 1909 onward.

In the case of Williams, a number of studies show the important role of the visual arts in the development of his poetics ${ }^{7}$. In linking Williams to the

Although Bernard Lecherbonnier (1983:28) contends that one cannot speak of a cubist movement in literature, except in a metaphorical way, he does acknowledge the fact that a number of French poets (including Apollinaire, Max Jacob and Paul Morand) shared the same principles as the visual artists, specifically in moving away from representation to creation. Lecherbonnier's statement seems to indicate a focus on the 'concrete' visual elements of cubism, whereas the style gains its force particularly from the principles guiding it. A poetic style sharing these elements is consequently no less cubist for not being imbued with such 'concrete' visual characteristics.

In his review of Steven Watson's Strange Bedfellows: The First American AvantGarde (1992:26), Arthur C. Danto accordingly states that the Armory Show "especially moved William Carlos Williams, who felt that the modern works constituted as much a break for poetry as for painting, "Verse to be alive must have infused into it some tincture of disestablishment, something in the nature of an impalpable revolution' he wrote to Harriet Monroe".

Danto further singles Williams out as an exception to other modernist poets in that his poetry was strongly influenced by the history of the visual arts.

7 The most prominent of these are works by Bram Dijkstra and Christopher Macgowan. In Dijkstra's Cubism, Stieglitz, and the Early Poetry of William Carlos Williams: The Hieroglyphics of a New Speech (1978), the atmosphere surrounding the New York Armory Show is shown to have had a profound influence on Williams, particularly through the contact established with the photographer Alfred Stieglitz and the circle of artists surrounding his art gallery. Macgowan's William Carlos Williams's Early Poetry: The Visual Arts Background (1984) also deals 
painters, however, critics tend to explore the visual aspects of his poetry to the extent of ascribing excessive importance to elements such as the arrangement of the words on the page, implying that his work moves in the direction of concrete poetry (where words are positioned on the page to form a picture). Although the appearance of the poem on the page is hardly irrelevant, the topography of the words contributing to the cubist quality of some poems (e.g. Poem XXV [CP 1:231 $]^{8}$ ), Williams' use of cubist principles in his style generally focus more on elements such as intersecting planes and the juxtaposition of sensory dimensions.

Of particular interest to Williams were the perspectives of the Cubist paintings that "define the identity of things as the view one takes of them" (Mazzaro, 1973:40) - an example being the perspectives that reveal the identity of the figures in Picasso's "Les Mademoiselles D'Avignon". In Williams' poetry the use of multiple perspectives works towards making the object of a poem "instantaneously perceptible" (Dijkstra, 1978:68) in the same way that a number of objects are brought together on the canvas of the painter. In order to determine whether these dimensions can be viewed as cubist, it is important to define the style in terms of its manifestations in poetry.

\subsection{Poetic cubism - an illustration}

Williams' "Spring Strains" (CP 1:97) is an example of a predominantly visual" cubist poem:

with this period in Williams' development but focuses more on the visual aspects in his poetry as a result of the influence of the work of the painters.

8 For purposes of reference, CP I refers to Williams, William Carlos. 1991. The Collected Poems of William Carlos Williams. Vol 1: 1909-1939. London : Paladin.

9 Visual in this sense implies not the spatial qualities of the poem, but rather the more abstract verbal equivalents of visual aspects (in other words description with words rather than depiction with paint). The term, visual cubist poem, used in this sense, would thus refer to a poem in which Williams makes extensive and primary use of and reference to the sense of sight (as opposed to a combination of senses) in presenting a scene. 
In a tissue-thin monotone of blue-grey buds crowded erect with desire against the sky

tense blue-grey twigs

slenderly anchoring them down, drawing them in -

two blue-grey birds chasing a third struggle in circles, angles, swift convergings to a point that bursts instantly!

Vibrant bowing limbs pull downward, sucking in the sky that bulges from behind, plastering itself against them in packed rifts, rock blue and dirty orange!

(Hold hard, rigid jointed trees!)

\section{But -}

the blinding and red-edged sun-blur creeping energy, concentrated counterforce - welds sky, buds, trees, rivets them in one puckering hold!

Sticks through! Pulls the whole counter-pulling mass upward, to the right locks even the opaque, not yet defined ground in a terrific drag that is loosening the very tap-roots!

On a tissue-thin monotone of blue-grey buds two blue-grey birds, chasing a third, at full cry! Now they are

flung outward and up - disappearing suddenly!

Dijkstra (1978:64) views the poem as being "an elaborate attempt at painting a Cubist picture in words"10. This 'painting' would again refer to

10 Marjorie Perloff (1981:124) questions the cubist qualities of Williams' early poems, stating that "To call Williams early poems 'Cubist', as does Bram Dijkstra, is, I think, to overstress the pictorial component of Cubist art". She then uses this poem to illustrate that what Dijkstra calls fragmented is still linear and although pictorial, merely "a sequence of clear visual images". In this argument Perloff nonetheless ignores the intersecting lines and planes in the poem as well as the 
the use of verbal equivalents for visual aspects. In the visual plane of the poem objects are isolated, analysed, and fragmented in a manner comparable to the fragmentation, isolation and breaking down of objects in Cubist paintings.

The cubist juxtaposition in this poem is evident in the first part as the "blue-grey buds", "blue-grey twigs", and "blue-grey birds" are linked by their colour, and yet clearly set against each other. There is also a sense of edges in words such as "anchoring", "sucking", and "plastering" that render invisible elements of the scene concrete or visual ${ }^{11}$, particularly in the movement described by the continuous nature of these actions. The rapid succession of a number of stressed, hard words such as "Hold, hard, rigid jointed trees" and "red-edged sun-blur", enhances this sense of edges.

The poem is also permeated with contrasts and intersecting planes, elements central to Cubist paintings. In the first stanza visual planes intersect as the buds (vertically erect) are juxtaposed with the sky (horizontal). The contrasts are particularly evident in the tensions present in the scene through words such as "tense", "anchoring", "rawing", "pull downward", "counterforce", and "counter-pulling".

These tensions, combined with the sense of movement ${ }^{12}$ in the poem, diverge from the more static qualities of most Cubist paintings. It nonetheless portrays a number of cubist qualities in elements such as intersecting planes and juxtaposition, with the advantage over the visual form of enabling the poet to create verbal equivalents for more than the merely static tactile elements of the scene. This is already an indication of the added

abstract fragmentation of the 'pictorial' scene that renders the poem distinctly cubist.

11 Dijkstra (1978:66) is of the opinion that these words materialize the space of the poem, transferring "the visual qualities ... of [this] space in painting to verbal equivalents", creating a "tactile visual space in language".

12 This use of movement also indicates a strong link to the style of Futurism which, although having a close relationship with Cubism, draws on elements such as movement and colour (additional to fragmentation) to create the unfamiliarity of experience and to convey perspective. An example is Marcel Duchamp's 'Nude Descending a Staircase" which creates a sense of movement and multiple perspective in consisting of a repetition of lines of a figure. 
force of cubist poetry that also emerges in the sensory dimension of Williams' poetry.

Cubism in poetry further strives for immediacy in bringing together a number of isolated details of a fragmented object or experience in a new synthesis. In "Spring Strains", immediacy is achieved primarily in the tension permeating the poem, although the final line brings an irrevocable fragmentation to the scene in something like an explosion: "flung outward and up - disappearing suddenly!" This element points to a distinction that can be made between two distinct types of Cubism (analytic and synthetic), also evident in Williams' poems.

Analytic Cubism concentrates more on the fragmentation of an object to a point of retaining almost no recognizable whole (which is the final effect of "Spring Strains"). Synthetic Cubism on the other hand, brings identifiable elements into one plane of relations where the object is preserved with a greater concern with design and unity in its technique, making the object more discernable. This second type of cubism leans heavily on foregrounding devices that accentuate the object of the poem, and Williams' use of sensory dimensions is an important method of such defamiliarization.

\section{Cubism in print}

The first prominent distinction between the cubism of the visual arts and Williams' cubism is the fact that the poem is not primarily visual in the sense of the visual arts (see footnotes 9 and 11). His cubism lies not in what we see on the page, but in what we read. An important implication of this is that the poet loses some of the immediacy available to the visual artist.

Dijkstra (1978:53) argues that a painting represents "a moment of perception", consisting of "a field of experience made instantaneously perceptible". Although this quality can to some extent be detected in a poem such as "Spring Strains" (CP 1:97), the immediacy of experience that is so central to Cubism has to be attained in another way in poetry. It is here that Williams' sensory dimension becomes important. By often making use of a number of senses rather than sight exclusively, Williams' 
poems create a more complete moment of experience, compensating to some extent for the lack of visual immediacy.

It is therefore important to keep in mind that the moment of experience presented in a poem, unlike in a painting, only becomes manifest after the reading of the poem. In this process of reading, the poet 'dictates' a certain order of perception or experience to the reader in presenting the elements of the scene ${ }^{13}$ in a specific order, an order that is not forced on the beholder of a painting. The scene presented in a poem cannot be taken in at a glance as in a painting. Unlike a painting, where the beholder views the final product, a poem takes the reader along in the process of creating an image or experience. In poetry the reader thus becomes part of the process of creation. When a poet thus achieves the effect of a painting with a poem or 'poetic unit', he/she is still not entirely able to produce something with the same immediately perceivable qualities ${ }^{14}$.

On the other hand, the poet has some advantages over the visual artist in that the final product is more easily discernable, a wheelbarrow being presented as such and not as a combination of a number of geometrical forms. Although this seems to indicate that the media are incompatible, it is especially this characteristic of the poem that brings it closer to synthetic Cubism, dealing with a discernable object and focusing on a number of shifting planes.

In "Trees" (CP I:98) Williams employs a number of these cubist techniques in rendering the scene by means of shifting and intersecting planes that are largely dependent on a sensory dimension.

The most obvious of these are the use of colour (shades of black), intersecting lines and planes, and juxtaposition. What is also evident in the poem is the use of senses other than the visual to enhance the quality of the experience. In this regard the kinaesthetic elements of the poem are particularly important.

13 Scene in this sense refers to all aspects of a situation, namely visual, auditory, tactile, olfactory, taste in short, experience.

14 In saying this I do not, however, imply that Williams attempts to copy the style of the visual artists. His cubism, although sharing certain characteristics with visual cubism, is still independent. 
In this 'black and white' 'picture', the tree is the focal point towards which all other forces converge:

Crooked, black tree

on your little grey-black hillock,

ridiculously raised one step toward

the infinite summits of the night:

even you the few grey stars

draw upward into a vague melody

of harsh threads.

Apart from the geometrical form and colour introduced in the first line, this stanza also introduces a number of rising vertical lines in which the "vague melody" is central. The lines and intersecting planes of "black tree", "grey-black hillock", "infinite summits of the night" and "grey stars" are extended to that of this melody "of harsh threads", combining form, colour, and sound in an intersection of various shades of black.

The figurative use of sound in making the "vague melody / of harsh threads" the apex to which the lines originating in the tree are drawn, augments the experience while at the same time foregrounding the "indivisible unfamiliarity" (Mathews, 1988:289) permeating it.

In the second stanza this effect is increased as the music metaphor is extended, working with the lines and intersecting planes and strong contrast and tension towards the presentation of a defamiliarized experience:

Bent as you are from straining against the bitter horizontals of a north wind, - there below you how easily the long yellow notes of poplars flow upward in a descending scale, each note secure in its own posture - singularly woven.

Again the first word signals these lines and planes, visually indicating the tension or "straining" of the tree against the horizontal force exerted by the wind (contrasted to the vertical force exerted by the stars). The force of the music metaphor increases with the juxtaposition of the "vague melody / of harsh threads" into which the tree is drawn and the "long yellow notes" (of the poplars below the tree) that "flow upward". 
The tension created in the first line of the stanza with the words "Bent" and "straining", is also augmented by the contrast (having an effect similar to the 'conceit' of the Metaphysical poets where seemingly disparate elements are brought together) in line five between the upward flow of the notes and their "descending / scale". This again indicates the cubist complication of the experience of the present moment, obscuring the picture and necessitating conscious attention. The isolated elements of experience are further foregrounded in the two final lines of the stanza with "each note secure in its own / posture, singularly woven". This adds another cubist dimension to the poem that is at the same time sensory, with the visual aspects of the scene described in aural metaphor.

In the final stanza the fragments of the metaphor are synthesised in a final contrast:
All voices are blent willingly
against the heaving contra-bass
of the dark but you alone
warp yourself passionately to one side
in your eagerness.

The tree itself, however, remains fragmented in the centre of the scene as its bent state (warping itself "passionately") indicates its isolation from the other voices, thus juxtaposing it with the "heaving contra-bass" of the darkness. Again a number of planes intersect in the plane of the tree, the only level in the poem which is never directly linked to the music metaphor.

The juxtaposition of this metaphor of sound with the visual presentation of the tree not only defamiliarizes the tree as the centre of the poem, but also augments the cubist force of the presentation that finally achieves a sensory dimension.

According to J. Hillis Miller (1966:316), "Williams' kinaesthetic poems transcend the limitations of abstract space and bring into existence a realm in which all places are everywhere" in the space created by the words of the poems. In this poem the music metaphor, and the resulting involvement of the aural sense, become a realm encompassing all elements of the scene in an overwhelming sound-space that reveals the obscure nature of perception of experience/scenes. 
This kinaesthetic characteristic of cubist poetry often recurs in Williams' poems of this period as he continually endows an object in one plane of relation with a characteristic from another (in the previous poem this can be detected in the use of an aural metaphor to describe visual characteristics). This technique primarily serves to foreground an element of a scene in order to give it autonomous existence in keeping with the tendency of synthetic Cubism.

This foregrounding device not only results in defamiliarization, but also indicates Williams' use of a sensory dimension to present the complexity of experience. This emphasises another fundamental difference between the cubist poem and the cubist painting in the presentation of the moment of perception in that the complete experience (with all its sensory elements) is striven for in a poem.

Williams' poems are nonetheless cubist in the way that the moment of perception is presented by means of intersecting planes that defamiliarize the elements of experience, revealing the unfamiliarity of experience, and not so much in the immediacy of the product or poem.

E.H. Gombrich (in Riddel, 1974:17) reasons that cubism disallows us the reference point of an ideal meaning: it "scrambles clues". The "obscurity" of the cubist painting is not lost in Williams' poetry, however, being achieved in the use of time-shifts, multiple points of view, reappraisals and erratic presentation as evident in Poem IX (CP 1:200) in Spring and All:

What about all this writing?

O "Kiki"

O Miss Margaret Jarvis

The backhandspring

I: clean

clean

clean: yes . . New York

Wrigley's, appendicitis, John Marin:

skyscraper soup -

As with a cubist painting, a cubist poem often renders something new that is hardly obvious and that has to be worked for. 
The visual unity of a painting is further manifested in poetry in the 'projection' of several aspects of an object onto a page in a poetic unit, creating an effect that is no less powerful than the visual form due to the condensed nature of poetry (as opposed to prose).

The dimensionality of the synthetic Cubist collage is another aspect of visual art that is rather difficult to translate into poetry, primarily because of the introduction of concrete material from everyday life. This very attempt to bring art closer to life and to remove it further from 'copying' or imitating nature, is nonetheless also central to Williams' poetics. Apart from creating edges similar to that of the collage by means of vocabulary, poetry/prose contrasts, and 'hardness', Williams also introduces everyday speech patterns in his poems, thus bringing elements of real life into his poetry. A clear example of this is the Spring and All poem "Shoot it Jimmy!", or Poem XVII (CP 1:216), in which the colloquial language brings the poem closer to life:

\footnotetext{
That sheet stuff

's a lot a cheese.

Man

gimme the key

and lemme loose -

I make 'em crazy
}

The experience of the present moment is defamiliarized as each word acquires an almost tactile quality within the erratic presentation of isolated fragments of dialect.

Williams' use of the senses, however, is even more significant in regard to the defamiliarization of experience. By involving more than one sense in the moment of 'perception', Williams imparts a synthetic Cubist dimensionality to his poems, and also creates a presentation of experience that is as 'vivid' as the visual attempts. This is partly what is implied by the term sensory dimension.

According to Marjorie Perloff (1983:173), Williams' poems of the late teens present his "first attempt to create verbal-visual counterparts to the paintings and drawings" of the visual arts. In the three major works pro- 
duced in the years 1917 to 1921, namely Al Que Quiere!, Sour Grapes, and Spring and All, there is a definite move in Williams' work towards the style of synthetic Cubism.

Although the scope of this article could not allow a comprehensive investigation of the development of Williams' style and the role of the sensory dimension in this development, the analyses of a few more poems produced in this period should go some way towards establishing the import of this element in Williams' cubism.

\section{The senses in action}

Williams' cubist style of creating a 'picture' in the form of a sensory experience is again evident in "To waken an old lady" (CP 1:152) with every aspect of the scene intensified in the tactile, aural and visual planes intersecting in the poem. In this sensory 'symphony' the experience of old age is defamiliarized in a synthesis that creates an edged presentation:

Old age is
a flight of small
cheeping birds
skimming
bare trees
above a snow glaze.
Gaining and failing
they are buffeted
by a dark wind -
But what?
On harsh weedstalks
the flock has rested,
the snow
is covered with broken
seedhusks
and the wind tempered
by a shrill
piping of plenty.

The edges are evident in both the irregularity and brevity of the lines, and in the use of words such as "bare trees", "harsh weedstalks", and "broken seedhusks". The cubist quality of the poem is further enhanced by the intersecting of aural and visual planes in "small cheeping birds", of tactile and visual planes in the defamiliarized "buffeted / by a dark wind" and 
"harsh weedstalks", and of tactile and aural planes in "the wind tempered / by a shrill / piping of plenty".

The figurative level of the poem at first seems uncharacteristically conspicuous, keeping in mind Williams' dislike of metaphorical language ${ }^{\text {is }}$ for its representing character, taking away the spontaneity of presentation. The kinaesthetic qualities as well as the bare edges and constantly intersecting planes nonetheless create a presentation in which the immediacy of perception and experience of the present is dominant, rendering the initial metaphor less obtrusive through defamiliarization.

Another Al Que Quiere! poem, "Love Song" (CP 1:79), again reveals the force of Williams' sensory dimension in creating vivid perceptions.

The scene presented is rendered vivid not only by the compact nature of the poem, but also in the combination of the simple language and exact words of imagism with elements characteristic of cubism such as juxtaposition and contrast in intersecting planes. This is evident in the last part of the first stanza as well as in the second stanza where the cubist edges are particularly visible:

The elm is scattering
its little loaves
of sweet smells
from a white sky!
Who shall hear of us
in the time to come?
Let him say there was
a burst of fragrance
from dark branches.

The sensory dimension of the poem gives the rendering of the experience of the scene a sensuous vividness as the fragrance emitted by the elm is defamiliarized as being scattered in the form of regular or symmetrical units "from a white sky".

15 In Spring and All, Williams writes: “... meanings have been lost through laziness or changes in the form of existence which have left words empty ... It is typified by use of the word 'like' or that 'evocation' of the 'image' ..." (CP 1:188). In this Williams expresses his view on the importance of imagination in rendering things new. 
In the second stanza this is given an abstract figurative dimension in the juxtaposition of the "sweet smells" of the tree with the way in which the speaker pronounces the wish to be remembered, together with his love, as "a burst of fragrance / from dark branches". The juxtaposition of the "sweet smells" with the "fragrance" is further intensified by the contrast between their respective sources, namely "white sky" and "black branches", as well as by that between the ways in which they are emitted, namely by "scattering' and as a "burst".

This juxtaposition of the senses of smell and sight (together with cubist geometrical form in the first stanza and the sense of hearing in the second stanza), results in a cubist rendering of an experience that transcends the merely visual experience of the visual arts. The visual is definitely not the primary sensuous level, intersecting with the olfactory and aural levels to create a composite experience.

In "Smell" (CP:92) Williams' sensory dimension centres in the sense of smell rather than that of sight as is the case in most of his cubist poems. On this olfactory plane the experience of spring is defamiliarized as the less fragrant of the smells of the season is exposed by the nose of the speaker. By means of the sense of smell as well as that of taste (the two senses being very close together) the unfamiliarity of the experience of the season is shown.

The poem creates an intensely cubist 'scene' by means of the intersection of different planes. In addressing his nose as a separate and independent persona, the speaker defamiliarizes not only the nose, but also what the nose smells:

Oh strong-ridged and deeply hollowed nose of mine! what will you not be smelling?

What tactless asses we are, you and I boney nose

always indiscriminate, always unashamed, and now it is the souring flowers of the bedraggled

poplars: a festering pulp on the wet earth

beneath them. With what deep thirst

we quicken our desires

to that rank odor of a passing springtime!

In focusing on the "souring flowers" and "rank odors" of a spring that is passing, the season that is usually associated with new life and appealing 
fragrances is defamiliarized, acquiring a prominence that is further accentuated by the arrangement of planes. The planes related to the nose (those of shape in its form and structure, and autonomy in smelling, tasting and knowing everything) are separated from those of the smells, a separation that is similar to that of the nose from the speaker.

In this defamiliarization and in the intersecting planes, the poem achieves a cubist character in spite of the fact that the presentation is not as visually vivid as in some of the other poems of this period. The poem is an excellent example of Williams' use of the senses to create a cubist presentation that transcends the visual aspects of a scene.

\section{Conclusion}

"In general", according to Schmidt (1988:7), "Williams used the inspiration he gained from the arts not to write poems about pictures or even to create a visual poetics, but to return to and renew specifically literary traditions and modes". In terms of the poems discussed in this article this opinion seems particularly valid.

In the constant renewal of traditions and modes, Williams employs a number of techniques of defamiliarization. As seen in these poems, the cubist intersection of particularly sensory planes creates a sensory dimension that not only renews the traditions and mode of poetry (here referring specifically to the role of perception in creating rather than representing experience), but also reveals the cubist characteristic of a concern with "the indivisible unfamiliarity which permeates our experience of the present" (Mathews, 1988:8).

In the senses Williams succeeds in foregrounding fragments of experiences that neither traditional literary nor visual works generally attain. In his sensory dimension we can also detect the beginnings of a style that infuses the literary work with elements from real life and that is used extensively in the books of Williams' prose poem "Paterson".

Williams' cubism, however, does not rely on the sensory dimension of his poems only. In many of the poems from this period the major cubist component is visual, and most of the poems depend on vocabulary, syntax and punctuation to create cubist edges, and on intersecting lines and planes along with these edges to defamiliarize a scene. The sensory dimension 
nonetheless adds a complexity to the poetry that succeeds in revealing the 'unfamiliarity' of the experience of the present moment. Williams' cubism does not make any indispensable distinction between the use of this sense and that of any other sense in creating a cubist effect.

The sensory dimension of the poems that distinguishes Williams' cubism from that of the visual artists is also enhanced by the use of movement that frequently occurs in the poems, giving them an added dimensionality.

Ultimately Williams' cubist poems reveal a delight in novelty, manifested in defamiliarization, which endows his poetic style with a spontaneity that remains with him throughout his career. In his inclusion of the senses and emotions in the imaginative use of planes, Williams' poems acquire a warmth and immediacy that expels clinical precision without disposing of visuality.

William Carlos Williams' cubist sensibility is perhaps most aptly described by Peter Schmidt (1988:7) when he says that what strikes him most in Williams' poetry is the "variety, not the consistency, of his theories and methods of writing, and ... the fact that such pluralism is reflected in the art world that Williams knew, particularly among the Precisionists, Cubists, and Dadaists". In the sensory dimension of his poetry, these qualities are strikingly sustained.

\section{Bibliography}

Burbick, Joan. 1982. Grimaces of a New Age: The Postwar Poetry and Painting of William Carlos Williams and Jackson Pollock. Boundary 2, 10(3):109-123, Spring.

Danto, Arthur C. 1992. In Bed with R. Mutt. Times Literary Supplement: 26, January 31.

Dijkstra, Bram. 1980. Sight as a Censor: William Carlos Williams' "March" as a Turning Point in the Poet's Career. In: Yearbook of Comparative and General Literature, 29:10-18.

Lecherbonnier, Bernard. 1983. Alcools, d'Apollinaire. Paris : Nathan.

MacGowan, Christopher J. 1984. William Carlos Williams's Early Poetry: The Visual Arts Background. Michigan : UMI Research Press.

Mathews, Timothy. 1988. Apollinaire and Cubism? Style, 22(2):275-298, Summer. 
Mazzaro, Jerome. 1973. William Carlos Williams: The Later Poems. Ithaca : Cornell University Press.

Miller, J. Hillis. 1966. Poets of Reality. London : Oxford University Press.

Perloff, Marjorie. 1981. The Poetics of Indeterminacy: Rimbaud to Cage. Princeton : Princeton University Press.

Perloff, Marjorie. 1983. 'To Give a Design': Williams and the Visualization of Poetry. In: Terrell, Carrol F., (ed.). William Carlos Williams: Man and Poet. Orono: University of Maine at Orono. p. 159-186.

Riddel, Joseph N. 1974. The Inverted Bell: Modernism and the Counterpoetics of William Carlos Williams. Baton Rouge : Louisiana State University Press.

Schmidt, Peter. 1988. William Carlos Williams: The Arts and Literary Tradition. Baton Rouge : Louisiana State University Press.

Shaw, 1972. The Dictionary of Literary Terms. New York : McGraw-Hill Book Company.

Williams, William Carlos. 1991. The Collected Poems of William Carlos Williams. Vol 1: 1909-1939. London : Paladin. 
